\title{
Enrichment of organic pollutants in the sea surface microlayer (SML) at Terra Nova Bay, Antarctica: influence of SML on superficial snow composition
}

\author{
Alessandra Cincinelli, ${ }^{* a}$ Angela M. Stortini, ${ }^{b}$ Leonardo Checchini, ${ }^{a}$ Tania Martellini, ${ }^{a}$ \\ Massimo Del Bubba ${ }^{a}$ and Luciano Lepri ${ }^{a}$ \\ ${ }^{a}$ Department of Chemistry, University of Florence, Via della Lastruccia, 3 - 50019 Sesto \\ Fiorentino,Florence, Italy.E-mail: acincinelli@hotmail.com; acincinelli@unifi.it; \\ Fax: +39-55-4573385; Tel: +39-55-5253324 \\ ${ }^{\boldsymbol{b}}$ Institute for the Dynamics of Environmental Processes (CNR-IDPA), Calle Larga Santa \\ Marta 2137, I-30123 Venice, Italy
}

Received 23rd May 2005, Accepted 28th September 2005

First published as an Advance Article on the web 19th October 2005

Concentrations of dissolved and particle-associated n-alkanes, phthalates and polycyclic aromatic

hydrocarbons (PAHs) were measured in sea surface microlayer (SML) and sub-surface water (SSL) samples collected in the coastal area of Terra Nova Bay, Antarctica, during the Austral spring 1998/1999. SML concentrations of the selected organic compounds were higher than SSL values and the enrichment factors were greater in the particulate phase than in the dissolved phase. During the same campaign, "fresh" snow samples, collected at different altitudes (from sea level up to $2670 \mathrm{~m}$ ) near the coast on Mt Melbourne, immediately after a snowy event, were analysed in order to provide more information on air/sea exchange processes. The same classes of organic compounds found in sea water were also present in "fresh" snow samples. The surfactant fluorescent organic matter (SFOM), adsorbed on the microdrop aerosol surface, could be considered the main constituent of the enrichment and the carrier at higher altitudes of organic compounds. In fact, hydrocarbons (n-alkanes and PAHs), which are not surfactants like phthalates, could interact with SFOM and follow the same fate.

\section{Introduction}

The Antarctic region is one of the most pristine areas in the world. Despite its remoteness, it exhibits evidence of marine contamination from scientific support activities, tourism, fishing and disposal practices. ${ }^{1}$ The present level of contaminants is not only related to local sources but also referred to the longrange transport from lower latitudes (such as via the atmosphere, water currents, sea-ice drift), depending on weather conditions and on the physico chemical properties of the compounds.

Sea surface film is considered as a gradient-region with its own physical, biological and chemical properties. ${ }^{2}$ Many attempts have been made to measure the concentrations of various natural and anthropogenic contaminants in the sea surface microlayer (SML), ${ }^{3-9}$ but, from our knowledge, SML concentration data are not available in the Ross Sea coastal waters, Antarctica. SML is generally considered to be enriched relative to sub-surface water (SSL) with a wide variety of chemicals concentrated to the air-sea interface because of their surfactant nature, hydrophobic properties, possible association with floatable particles, vertical diffusion mechanisms or bubbles scavenging. The transfer of such chemicals from and across the sea surface microlayer to the atmosphere may take place through the volatilization due to those compounds with high vapor pressure, the stripping by the bubbles and the formation of wind generated aqueous aerosol. ${ }^{6,10-14}$ In fact, when air bubbles burst at the sea surface they generate an aerosol which is contaminated and enriched with material scavenging from the SML and the water column. ${ }^{8}$

Antarctic coastal areas are directly exposed to marine air masses and coastal snow appears to be a very good aerosol sampler in those conditions (salt storms) in which all other expected aerosol contributions (continental, anthropogenic, volcanic) are minimal. ${ }^{15}$ Snow is the only possible wet deposition present in the Antarctic region, and the snow sampling at stations located in different geographic positions (altitude and distance from the sea) can give useful information about aerosol sources and transport processes (such as short and long-range transport and fractionation effects). In fact, material present in the marine aerosol and atmosphere can be incorporated into snowfalls or falls onto the snow surface by dry deposition. Hence, the concentrations of airborne contaminants in the snow represent an unambiguous record of the local atmospheric composition and can be used for estimating pollutant levels in the region. ${ }^{16}$

This paper reports results for hydrocarbon analyses (n-alkanes and PAHs) and, for the first time, their enrichments in SML samples collected in the coastal area of Terra Nova Bay, Antarctica during the Austral spring 1998/1999. The study was also broadened to include phthalate esters, since they represent a class of synthetic chemicals most extensively employed in many industrial applications, ${ }^{17}$ and as a consequence, evidences of their widespread presence in different environmental matrices, have been documented. ${ }^{18-20}$ In addition, phthalate contamination of remote regions, such as Antarctic marine environment, has been elsewhere reported, ${ }^{21-23}$ suggesting that long-range transport could play an important role in the transfer of such compounds from industrial to remote areas.

As part of our efforts to understand the correlation between sea surface microlayer and snow composition, "fresh" snow (that is collected as soon as possible after deposition so as to avoid alterations due to photochemical reactions and/or me- 
teorological events) was sampled near the coast on Mt Melbourne during the same campaign. The monitoring of these contaminants should give an indication of the degree to which the remote area is exposed, and analysis of snow samples could be useful to better evaluate the role of marine aerosol in the transport of organic compounds from the air/sea interface to coastal zones and its contribution to the chemical composition of the snow. The presence of high concentrations of $\mathrm{NaCl}$ in coastal Antarctic snow has been attributed to a marine aerosol contribution. ${ }^{21,24,25}$ Therefore, organic compound concentrations in snow samples can depend on the different composition of marine aerosol with respect to the sea water and on the distance from the coast and altitude above sea level (a.s.1.) of the snow sampling site. In order to better understand this phenomenon, it is necessary to calculate the ratios between the concentration of organic compounds in snow and sea water samples with respect to the concentration of sodium ion in the same matrices. In fact, sodium ion can be used as a reference component because it is not enriched during the aerosolization process and its concentration can be taken as a quantitative index of marine aerosol content in the snow. ${ }^{21,24,25}$

\section{Experimental}

\section{Sampling sites}

In the framework of the Italian Research Program in Antarctica (PNRA) sea surface microlayer (SML) and sub-surface water (SSL) samples were collected during the 1998/1999 Austral spring in a near shore station located in the Gerlache Inlet area, at Terra Nova Bay, Victoria Land, Antarctica (430 $\mathrm{m}$ deep; distance from the coast $>7 \mathrm{~km}$, see Fig. 1). This area was chosen because considered free from research station influences and maritime traffic.

SML and SSL samples were collected under calm sea conditions, by Multi-Use Microlayer Sampler (MUMS) ${ }^{8,26}$ which is based on the method proposed by Harvey. ${ }^{27}$ Briefly, the sampler consisted in a radio-controlled catamaran, with a Pyrex glass rotating drum $(315 \mathrm{~mm}$ diameter, $500 \mathrm{~mm}$ length, $6 \mathrm{rpm}$ speed). The material adsorbed on the drum surface was removed by a Mylar scraper. The collected liquid was carried to a pre-cleaned stainless steel bottle by a Teflon membrane

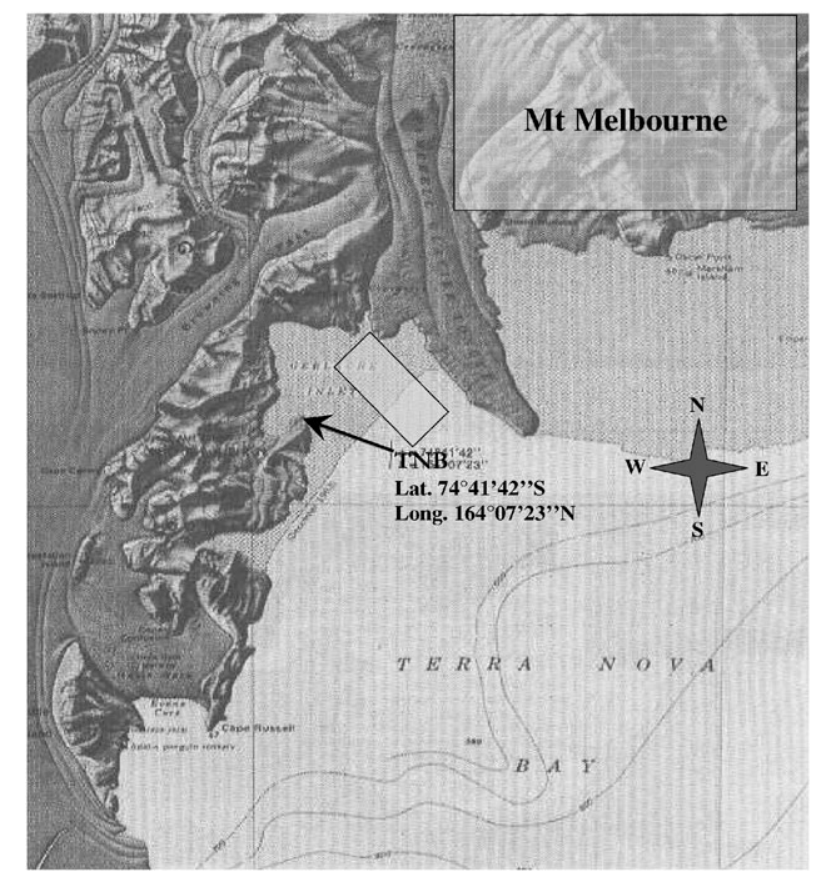

Fig. 1 Map of Terra Nova Bay, Victoria Land, Antarctica. The light squares denote the SML and SSL sampling-area and Mt Melbourne. The position of the Italian Antarctic summer base is also shown.
Table 1 (a) Sampling dates for SML and SSL during the 1998-1999 Antarctic campaign. (b) Sampling dates for snow samples during the 1998-1999 Antarctic campaign.

(a)

\begin{tabular}{llll}
\hline Sample & $\begin{array}{l}\text { Sampling date } \\
(\mathrm{mm} / \mathrm{dd} / \mathrm{yy})\end{array}$ & $\begin{array}{l}\text { Sea } \\
\text { condition }\end{array}$ & $\begin{array}{l}\text { Air } \\
\text { temperature } /{ }^{\circ} \mathrm{C}\end{array}$ \\
\hline SML1 + SSL1 & $01 / 23 / 99$ & Calm & $-1 /+1$ \\
SML2 + SSL2 & $01 / 28 / 99$ & Calm & $-2 /+1$ \\
SML3 + SSL3 & $02 / 02 / 99$ & Calm $^{a}$ & $-4 /-2$ \\
SML4 + SSL4 & $02 / 04 / 99$ & Calm $^{a}$ & $-4 /-2$ \\
\hline
\end{tabular}

(b)

Sampling date Sea $360 \mathrm{~m}$ above $1188 \mathrm{~m}$ above $2670 \mathrm{~m}$ above $(\mathrm{mm} / \mathrm{dd} / \mathrm{yy}) \quad$ level sea level sea level sea level

\begin{tabular}{|c|c|c|c|}
\hline $11 / 29 / 98$ & $x$ & & \\
\hline $11 / 30 / 98$ & $x$ & $x$ & $x$ \\
\hline $12 / 13 / 98$ & $x$ & $x$ & $x$ \\
\hline $12 / 28 / 98$ & $x$ & $x$ & $x$ \\
\hline $01 / 09 / 99$ & $x$ & $x$ & $x$ \\
\hline
\end{tabular}

${ }^{a}$ Sudden wind gusts.

pump. The rotating drum, as well as the collector pipe line, was washed with sea water for 10 minutes before sampling. The flux of collected liquid was switched in the bottle or in the sea by a Teflon solenoid three-way valve. The whole line for microlayer and sub-surface collection was in Teflon. Sub-surface water was collected by the switching of microlayer line to the subsurface, around $0.5 \mathrm{~m}$ from the sea surface. The catamaran, as well as the rotating drum, pumps and valves, was electrically powered. In Table la are reported sampling days, sea conditions and air temperatures for SML and SSL samples. All water samples were immediately frozen and kept at $-30{ }^{\circ} \mathrm{C}$ until analysis.

"Fresh" snow samples (about 40 litres) were taken near the coast along a transept at increasing altitudes on Mt Melbourne from $360 \mathrm{~m}$ up to $2670 \mathrm{~m}$. The sampling stations for "fresh" snow were the following: sea level, $360 \mathrm{~m}, 1188 \mathrm{~m}$, and $2670 \mathrm{~m}$ a.s.l. The sampling dates are reported in Table 1b. All samples were immediately kept at $-30^{\circ} \mathrm{C}$ until analysis.

\section{Reagents and materials}

Ultrapure water ( $>18 \mathrm{M} \Omega$ ) obtained from a Milli-Q system was used to extract glass fibre filters. Anhydrous sodium sulfate was heated for $12 \mathrm{~h}$ at $450{ }^{\circ} \mathrm{C}$ to remove any organic matter and kept at $120^{\circ} \mathrm{C}$ until use. Glass fibre filters GF/F (Whatman, USA) were pretreated at $450{ }^{\circ} \mathrm{C}$ for $12 \mathrm{~h}$. Solvents were all for organic trace analysis (Baker, Holland). Standard PAH mixture EPA 610 was commercially available from Supelco (Bellefonte, PA, USA) and included the following compounds: naphthalene (N), acenaphthylene (ACY), acenaphthene (AC), fluorene (FL), phenanthrene (PHE), anthracene (ANT), fluoranthene (FLT), pyrene $(\mathrm{PY})$, benzo $(a)$ anthracene $(\mathrm{BaA})$, chrysene $(\mathrm{CHR})$, ben$\mathrm{zo}(b)$ fluoranthene $(\mathrm{BbF})$, benzo $(k)$ fluoranthene $(\mathrm{BkF})$, benzo( a)pyrene (BaP), indeno(1,2,3-c,d)pyrene (IP), dibenzo $(a, h)$ anthracene (DBA) and benzo $(g, h, i)$ perylene (BghiP). Tetradecene, heicosene and triphenylbenzene were purchased from Alltech (Deerfield, USA).

All glassware and stainless steel bottles were cleaned before use by repeated washing with a hot mixture of chromic and concentrated sulfuric acid, ultrapure water and acetone and finally dried in an oven at $130{ }^{\circ} \mathrm{C}$ for $30 \mathrm{~min}$.

\section{Extraction of organic compounds}

Sea water samples were separated into particulate and dissolved phases by filtering through glass fibre filters (nominal 
porosity $=0.45 \mu \mathrm{m}$ ), using an all-glass vacuum holder (Sartorius, Florence, Italy). Sea salts were removed from the filters by rinsing with $20 \mathrm{ml}$ of ultrapure water. The extraction of dissolved organic compounds was performed with n-hexane by the replicated extractant enrichment method, according to Desideri et al. ${ }^{28}$ Before extraction, tetradecene, heicosene and triphenylbenzene were spiked into water samples and filters for recovery determination. Filters were treated with $32 \mathrm{ml}$ of ultrapure water and $8 \mathrm{ml}$ of methanol in a cold ultrasonic bath (Bransonic 3200, USA) and then extracted with $4 \mathrm{ml}$ of a n-hexane-methylene chloride mixture $1 / 1 \mathrm{v} / \mathrm{v}$ by magnetic stirring for 15 min..$^{8,29,30}$ The extraction procedure was repeated three times. The extracts were anhydrified with sodium sulfate and evaporated to $100 \mu \mathrm{l}$. The organic extracts were dried over anhydrous sodium sulfate, evaporated to $100 \mu \mathrm{l}$ under a gentle stream of nitrogen and then fractionated into three fractions of increasing polarity on a column $(0.6 \times 10 \mathrm{~cm})$ containing Silica gel $60 \mathrm{HR}$ (Merck), previously activated to $120{ }^{\circ} \mathrm{C}$ for $3 \mathrm{~h}^{30}$ This procedure allowed us to separate n-alkanes (fraction I) from PAHs (fraction II) and phthalates (fraction III). Fractions I and III were analysed on a Varian 4290 gas chromatograph-mass spectrometer (GC-MS), according to a procedure and a temperature program described elsewhere. ${ }^{8}$ Separation and identification of the investigated PAHs (FL, PHE, ANT, FLT, PY, BaA, CHRY, BbF, BkF, $\mathrm{BaP}$, DBA, BghiP and IP) were achieved according to Cincinelli et al., ${ }^{8}$ by using a Shimadzu (Milan, Italy) HPLC system equipped with two LC-10ADvp pumps, a photodiode array detector SDP M10AVP and a spectrofluorometric detector RF-551.

\section{Fluorescence spectra}

A Perkin Elmer LS50B Luminescence spectrometer was used to scan emission fluorescence spectra, $\left(\lambda_{\text {ex }} 308 \mathrm{~nm}, \Delta \lambda_{\text {em }} 320-\right.$ $630 \mathrm{~nm}$, em and ex slits $8 \mathrm{~nm}$, scan speed $360 \mathrm{~nm} \mathrm{m^{-1 }}$ ). From the emission spectra, we calculated the normalised fluorescence intensity $\left(I_{\text {norm }}\right)$ defined by:

$$
I_{\text {norm }}=I_{\max } / I_{\text {Raman }} \times 100
$$

Where $I_{\max }$ is the maximum fluorescence intensity of fulvic acid (FA) band (440-460 nm) and $I_{\text {Raman }}$ is the maximum intensity of the Raman peak water. ${ }^{31} I_{\text {norm }}$ is a quantity defined in arbitrary units, requires a calibration procedure ${ }^{32}$ and it is used here as an index of surfactant fluorescent organic matter (SFOM).

\section{Sodium ion analysis}

The sodium ion concentrations were determined by using portions of the water solution obtained by sonication. An ion chromatography apparatus Dionex 4500i equipped with a gradient pump, a conductivity detector (CDM-1) and an eluent gas module (EDM-2) were used for the determination of the inorganic ions. A Dionex CS10 column (eluent $=1.0 \mathrm{ml}$ $\min ^{-1}$ of $20 \mathrm{mM} \mathrm{HCl}+0.5 \mathrm{mM}$ diaminopropionic acid) followed by a CMMS-2 micromembrane suppressor was employed for cation separation. ${ }^{33}$ Chromatographic data acquisition and elaboration were performed by a Dionex AI-450 integration software.

\section{Blanks and detection limits}

Precautions were taken to avoid contamination in the laboratory. As reported elsewhere ${ }^{23,34}$ an analytical blank procedure was performed inserting highly purified water (40 1) in two stainless steel reservoirs in Antarctica and freezing them at $-30{ }^{\circ} \mathrm{C}$ until analysis.

The blank concentrations of organic compounds were $0.5-1.2 \mathrm{ng}^{-1}$ for phthalates, $0.7-1.1 \mathrm{ng}^{-1}$ for $\mathrm{n}$-alkanes
Table 2 Total concentration (ng $\mathrm{l}^{-1}$ ) of n-alkanes, squalene, phthalates and PAHs in SML and SSL samples and their relative enrichment factors $(\mathrm{EF})$

\begin{tabular}{|c|c|c|c|c|c|c|}
\hline & \multicolumn{3}{|c|}{ Dissolved phase } & \multicolumn{3}{|c|}{ Particulate phase } \\
\hline & SML & SSL & $\mathrm{EF}$ & SML & SSL & $\mathrm{EF}$ \\
\hline \multicolumn{7}{|l|}{ Sample 1} \\
\hline n-Alkanes $\left(\mathrm{C}_{15}-\mathrm{C}_{32}\right)$ & 532 & 298 & 1.8 & 767 & 574 & 1.3 \\
\hline CPI & 0.72 & 0.63 & & 0.67 & 0.66 & \\
\hline Squalene & 669 & 552 & 1.2 & 752 & 478 & 1.6 \\
\hline Phthalates & 184 & 147 & 1.3 & 238 & 123 & 1.9 \\
\hline PAHs & 7.79 & 2.39 & 3.3 & 8.94 & 3.19 & 2.8 \\
\hline \multicolumn{7}{|l|}{ Sample 2} \\
\hline n-Alkanes $\left(\mathrm{C}_{15}-\mathrm{C}_{32}\right)$ & 223 & 108 & 2.1 & 607 & 192 & 3.2 \\
\hline CPI & 0.49 & 0.47 & & 0.54 & 0.42 & \\
\hline Squalene & 321 & 101 & 3.2 & 681 & 171 & 4.0 \\
\hline Phthalates & 44.0 & 31.0 & 1.4 & 106 & 46.0 & 2.3 \\
\hline PAHs & 4.77 & 2.37 & 2.0 & 14.1 & 2.56 & 5.5 \\
\hline \multicolumn{7}{|l|}{ Sample 3} \\
\hline n-Alkanes $\left(\mathrm{C}_{15}-\mathrm{C}_{32}\right)$ & 301 & 248 & 1.2 & 377 & 290 & 1.3 \\
\hline CPI & 0.60 & 0.44 & & 0.51 & 0.44 & \\
\hline Squalene & 384 & 112 & 3.4 & 425 & 213 & 2.0 \\
\hline Phthalates & 168 & 82.0 & 2.0 & 125 & 63.0 & 2.0 \\
\hline PAHs & 4.67 & 2.24 & 2.1 & 5.68 & 1.65 & 3.4 \\
\hline \multicolumn{7}{|l|}{ Sample 4} \\
\hline n-Alkanes $\left(\mathrm{C}_{15}-\mathrm{C}_{32}\right)$ & 442 & 290 & 1.5 & 641 & 362 & 1.8 \\
\hline CPI & 0.88 & 0.56 & & 0.90 & 0.72 & \\
\hline Squalene & 447 & 293 & 1.5 & 521 & 358 & 1.5 \\
\hline Phthalates & 124 & 99.0 & 1.3 & 205 & 94.0 & 2.2 \\
\hline PAHs & 5.90 & 4.01 & 1.5 & 10.1 & 3.65 & 2.8 \\
\hline
\end{tabular}

and $0.003-0.006 \mathrm{ng} \mathrm{l}^{-1}$ for PAHs. The concentration levels reported in Tables $2-4$ were obtained by subtracting the blanks from the values measured by chromatograms.

Detection limits were calculated by doubling blank concentrations and, consequently, $2 \mathrm{ng} \mathrm{l}^{-1}$ for n-alkanes, $2.5 \mathrm{ng} \mathrm{l}^{-1}$ for phthalates and $0.012 \mathrm{ng}^{-1}$ for PAHs, were considered.

\section{Results and discussion}

Table 2 reports the total concentrations $\left(\mathrm{ng}^{-1}\right)$ of $n$-alkanes, phthalates, squalene and PAHs found in SML and SSL samples as well as the Enrichment Factor (EF) which is the ratio between the concentration of any substance in the SML and SSL samples collected at the same time. These classes represent almost all the organic substances extractable with nhexane and with n-hexane-methylene chloride for the dissolved and the particulate phases, respectively.

$\mathrm{n}$-Alkanes, having carbon numbers ranging from $\mathrm{C}_{15}$ to $\mathrm{C}_{32}$, were detected in all samples. Dissolved n-alkanes varied from 223 to $532 \mathrm{ng}^{-1}$ for SML and from 108 to $298 \mathrm{ng}^{-1}$ for SSL, while particulate n-alkanes ranged from 377 to $767 \mathrm{ng}^{-1}$ for SML and from 192 to $574 \mathrm{ng}^{-1}$ for SSL. Particulate matter was also systematically higher in the SML $\left(0.52-1.45 \mathrm{mg} \mathrm{l}^{-1}\right)$ than in SSL (0.48-0.76 $\left.\mathrm{mg} \mathrm{l}^{-1}\right)$, partially explaining the higher concentrations of particulate organic compounds in the surface microlayer to subsurface water.

Similar levels of dissolved n-alkanes were found in sea water ( $2 \mathrm{~m}$ deep) during previous expedition (36-260 $\left.\mathrm{ng}^{-1}\right)^{30}$ and in samples taken at the Davis Station, Eastern Antarctica, as reported by Green et al. ${ }^{35}\left(70-170 \mathrm{ng}^{-1}\right)$. However, lower (4.1-10.5 $\mathrm{ng}^{-1}$ ) and higher (1.1-21.8 $\mu \mathrm{g}^{-1}$ ) levels were obtained for the area of Bransfield Strait, Antarctica, by Sanchez Pardo and Rovira ${ }^{36}$ and Cripps, ${ }^{37}$ respectively. As suggested by Cripps and Priddle, ${ }^{38}$ strong variations in hydrocarbon concentrations throughout the Antarctic region could 
a)
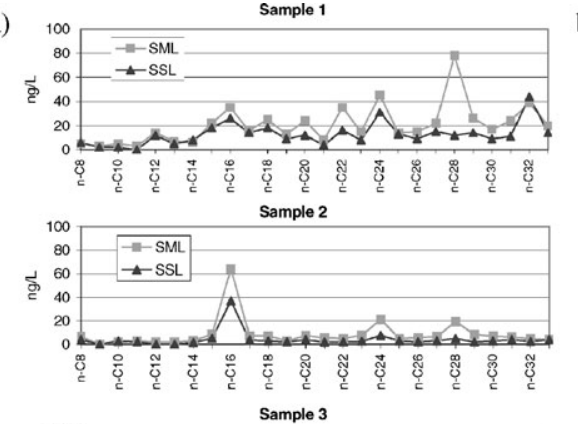

Sample 3

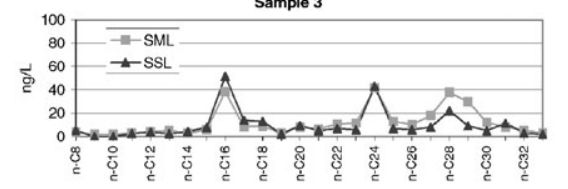

Sample 4

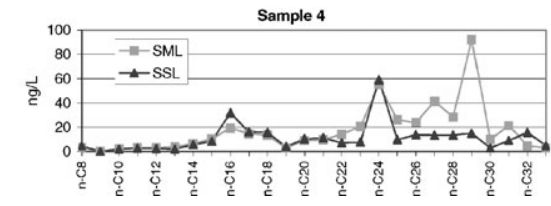

b)
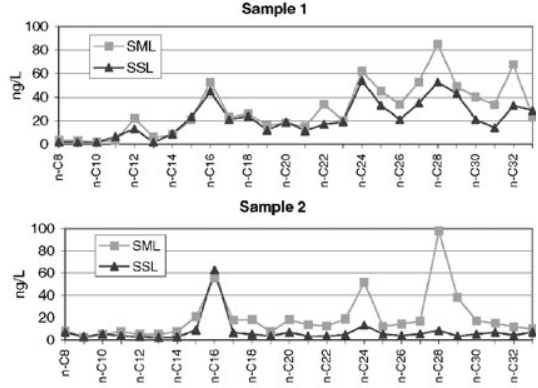

Sample 3

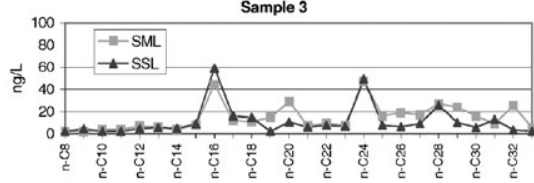

Sample 4

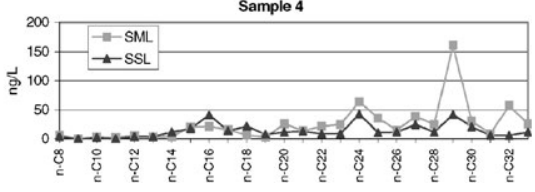

Fig. 2 n-Alkane distribution in dissolved phase (a) and particulate phase (b).

be explained by a complex combination of biological and physical properties of the ocean. This variability could be also related to possible contaminations of the sampling zones by anthropogenic hydrocarbons, due to isolated incidents (principally ship-wrecks), research station activities and shipping. In addition, as pointed out by Del Bubba et al., ${ }^{23}$ different hydrocarbon concentrations can be obtained at different sampling depths.

Distribution pattern for n-alkanes in the samples are shown in Fig. 2, for dissolved and particulate phases, respectively. As previously observed in sea water samples collected in the Ross Sea, ${ }^{21,23} \mathrm{C}_{16}, \mathrm{C}_{24}, \mathrm{C}_{28}$ n-alkanes were generally present at higher concentrations with respect to the other congeners, with the exception of sample 4, which showed a particular distribution with an absolute maximum for $\mathrm{C}_{29}$. In this regard it should be noted that a n-alkane distribution with an absolute maximum for $\mathrm{C}_{29}$ was observed for Euphasia superba, which is the main krill species present in this area. ${ }^{29}$ The Carbon Preference Index (CPI), which is the odd to even carbon number ratio for n-alkanes, calculated over the range $\mathrm{C}_{15}-\mathrm{C}_{32}$, can be useful to distinguish the natural contribution to the n-alkane content from petrogenic or anthropogenic contaminants. Values of about one could suggest petrogenic contamination, whereas odd carbon predominance can evidence terrestrial plants and marine algae contributions. Moreover, as shown by Cripps, ${ }^{37}$ odd/even ratios both less and higher than one have been found in pelagic organisms of the southern ocean and could, therefore, indicate a marine organism influence. CPI values were always found to be less than one in all the samples. In particular, values closer to one were determined in SML (range 0.49-0.88 and 0.51-0.90 for dissolved and particulate phase, respectively) than in SSL (range 0.44-0.63 and 0.42-0.72 for dissolved and particulate phase, respectively). Biogenic nalkanes would be expected to dominate the hydrocarbons at Terra Nova Bay between January and March, because it is the period of maximum phytoplankton biomass and sedimentation. ${ }^{39-40}$ Moreover, it is important to note that significant amounts of squalene were detected in all the samples (ranges: 321-752 $\mathrm{ng}^{-1}$ for SML and 101-552 $\mathrm{ng}^{-1}$ for SSL in dissolved phase; 42-752 $\mathrm{ng}^{-1}$ for SML and 171-478 $\mathrm{ng}^{-1}$ for SSL in particulate phase). This compound is an acyclic isoprenoid often used as a biological marker, originating mainly from the phytyl side chain of chlorophyll $a{ }^{41}$ These findings suggest a predominantly biogenic origin of n-alkanes. Odd to even ratios closer than one were observed in the SML dissolved and particulate phases of sample 4, owing to the very high concentration of $\mathrm{C}_{29}$ found in this sample.

The identification of polluting hydrocarbons in the environment is complicated, since many of these compounds also occur naturally. However, PAHs occur to a minor extent in nature than aliphatic hydrocarbons and may be employed as indicators of man's impact on the environment. ${ }^{37}$

In dissolved phase, PAH concentrations varied from 4.67 to $7.79 \mathrm{ng}^{-1}$ for SML and from 2.24 to $4.01 \mathrm{ng}^{-1}$ for SSL. The association between hydrocarbons and particulate is well known and is accentuated at low temperatures. ${ }^{42}$ PAH content of sea water particulate ranged from 5.68 to $14.1 \mathrm{ng} \mathrm{l}^{-1}$ in SML and from 1.65 to $3.65 \mathrm{ng}^{-1}$ in SSL. These data confirmed the enrichment of SML with respect to SSL, both for dissolved and particulate phase, as observed for n-alkanes.

The low concentrations observed in this campaign confirmed the still pristine character of the Antarctic environment.

The PAH levels reported in this paper can be compared with those present in literature for Antarctic sea water. High variations have been observed by different authors; for example Cripps, ${ }^{37}$ in a study concerning the Brainsfield Strait area, reported total PAH concentrations lower than the detection limit $\left(50 \mathrm{ng}^{-1}\right)$ at $43.5 \%$ of the sampling stations, while a further $43.5 \%$ had values in the range $50-500 \mathrm{ng}^{-1}$ and $13 \%$ $500-1700 \mathrm{ng} \mathrm{l}^{-1}$. In samples collected at the Signy research station (South Orkney Islands) the same author measured a total PAH content ranging from 50 to $200 \mathrm{ng} \mathrm{l}^{-1}$, depending on the distance from the coast. Much higher contents of total PAHs were observed in the Weddel Sea by Comes et al., ${ }^{43}$ who reported concentrations up to $9.4 \mu \mathrm{g} 1^{-1}$.

PAH distributions in the dissolved and particulate phases of SML and SSL sea water samples are presented in Fig. 3. FL, ANT, FLT, PY, BbF, BkF and BaP were detected in SML and SSL phases, in almost all the investigated samples. Among these analytes, Fl, ANT, FLT and Py were predominant in all samples as reported by Cripps ${ }^{37}$ for sea water samples collected in the Southern Ocean.

In Table 2, total phthalate concentrations are also reported. Phthalate esters are one of the most widely used classes of synthetic chemicals employed in industry today, and have become widely spread contaminants of the aquatic environment. ${ }^{20}$ Dimethyl, di-n-propyl, di-isobutyl, di-2-ethylhexylphthalates represent the whole class of phthalates; the last one gives a major contribution to total phthalates. The amount of phthalates varied from 44.0 to $168 \mathrm{ng} \mathrm{l}^{-1}$ for SML and from 31.2 to $147 \mathrm{ng}^{-1}$ for 
a)

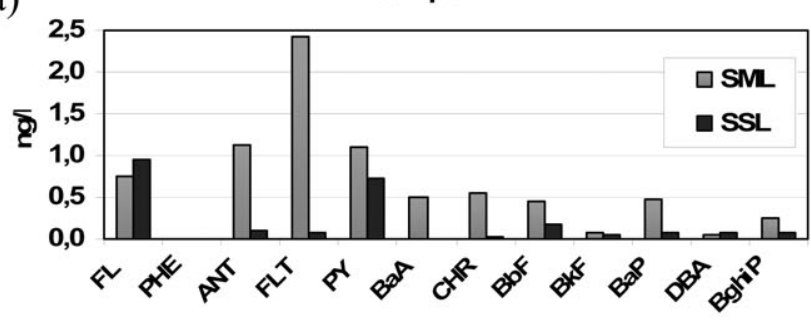

Sample 2

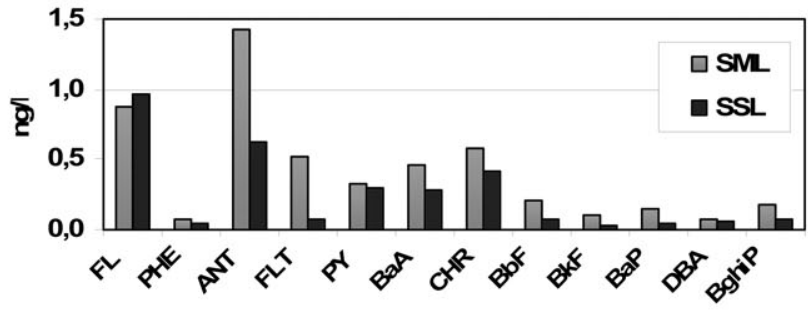

Sample 3

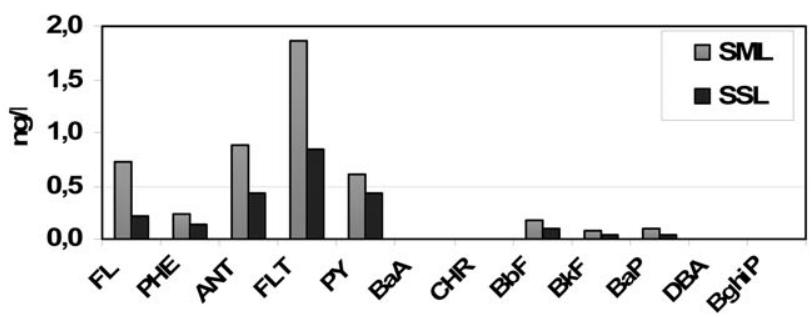

Sample 4

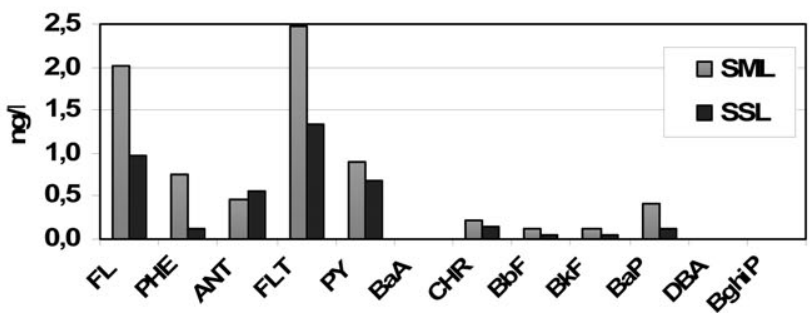

b) Sample 1

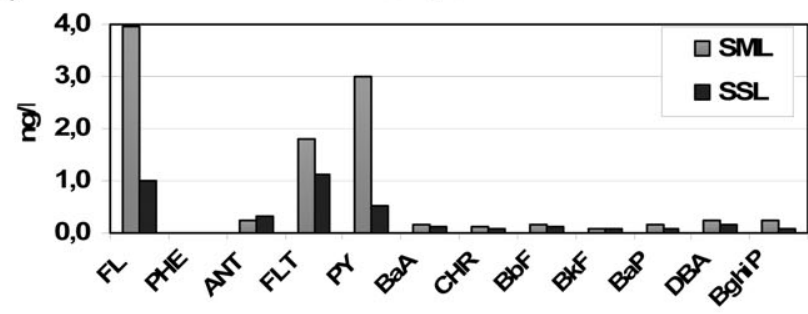

Sample 2

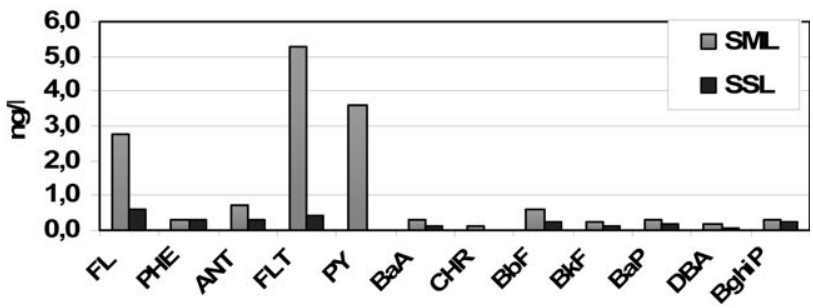

Sample 3

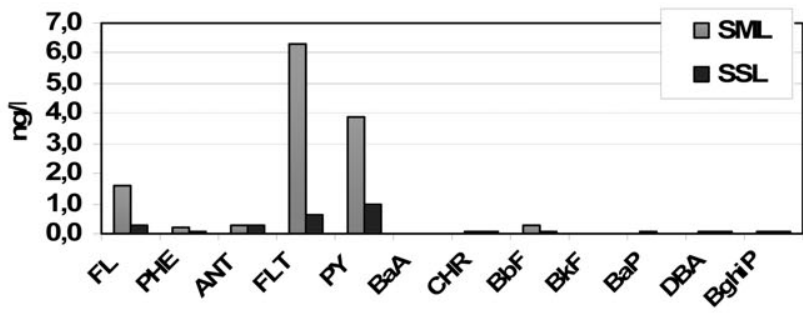

Sample 4

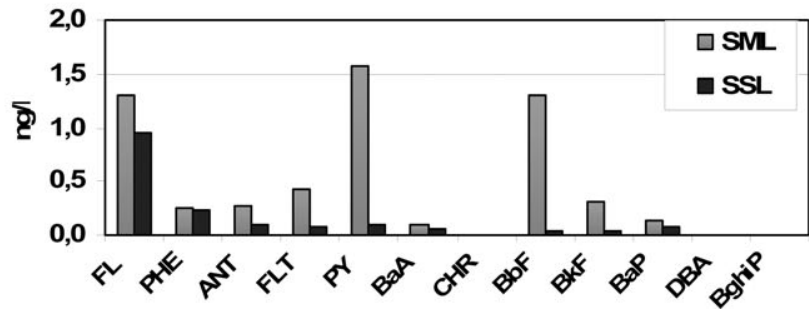

Fig. 3 PAHs distribution in dissolved phase (a) and particulate phase (b).

SSL in dissolved phase, and from 106 to $238 \mathrm{ng}^{-1}$ for SML and from 46.1 to $123 \mathrm{ng} \mathrm{l}^{-1}$ for SSL in particulate phase.

We were interested in the extent to which the microlayer is enriched relatively to subsurface water and this can be expressed in a dimensionless manner using the enrichment factor (EF). In all samples organic compounds are preferentially enriched in the sea surface microlayer (see Table 2). EF values of n-alkanes (range: 1.3-3.2), phthalates (range: 1.9-2.3) and PAHs (range: 2.8-5.5) in the particulate phase are for most samples higher than those dissolved (ranges: 1.2-2.1 for n-alkanes, 1.3-2.0 for phthalates, 1.5-3.3 for PAHs). Enrichment of particle associated PAHs in the SML was largely related to the preferential accumulation of particulate at the air /water interface.

\section{Snow samples}

Table 3 reports the mean total concentrations expressed in ng $1^{-1}$ of individual n-alkanes, squalene, phthalates and PAHs found in "fresh" snow samples collected at different altitudes on Mt Melbourne, located close to TNB. The results showed similar concentrations to those obtained during previous Antarctic campaigns. ${ }^{21,34}$

In Table 4, the distribution of individual n-alkane, PAH and phthalate concentrations were shown for sample collected at $360 \mathrm{~m}$ above sea level (sample 11/30/98), as representative of all "fresh" snow samples. The distribution of n-alkanes, ranging from $\mathrm{C}_{15}$ to $\mathrm{C}_{32}$, showed an odd to even carbon ratio varying from 0.52 to 0.98 , indicative of a mainly biogenic origin.

In addition, all "fresh" snow samples showed the presence of squalene and n-alkanes with the prevalence of $\mathrm{C}_{16}, \mathrm{C}_{24}$ and $\mathrm{C}_{28}$ as found in all sea surface water analyzed, confirming previous studies, ${ }^{34}$ which indicated these organic compounds to be markers of marine contribution to the chemical composition of snow.

PAH distributions and concentrations were found to be similar among the samples collected after the same precipitation event altough at different altitudes. Total PAH concentrations varied from 0.60 to $2.98 \mathrm{ng}^{-1}$, and the main PAH components detected were fluorene, anthracene, pyrene and chrysene.

The phthalate compositions were similar to that found in sea water samples and almost represented by di-n-butyl, di-isobutyl and di-2-ethyl-hexylphthalate. The presence of this class of organic compound in snow samples is also confirmed by finding on the Antarctic atmospheric particulates collected by Ciccioli et al. ${ }^{22 a}$ This study showed that samples of particulate organic matter, collected from January to February 1991, contained a significant amount of n-alkanes and phthalates. The authors hypothesized that some plasticizers (e.g. phthalates), have the same dispersion processes (probably due to their chemicophysical properties), since they are soluble in 
Table 3 Total concentration $\left(\mathrm{ng}^{-1}\right)$ of n-alkanes, squalene, phthalates and PAHs in snow samples collected at different altitudes

\begin{tabular}{|c|c|c|c|c|}
\hline & Sea level & $360 \mathrm{~m}$ & $1188 \mathrm{~m}$ & $2670 \mathrm{~m}$ \\
\hline \multicolumn{5}{|l|}{ Sample 11/29/98 } \\
\hline n-Alkanes $\left(\mathrm{C}_{15}-\mathrm{C}_{32}\right)$ & 353 & & & \\
\hline CPI & 0.32 & & & \\
\hline Squalene & 545 & & & \\
\hline Phthalates & 142 & & & \\
\hline PAHs & 1.21 & & & \\
\hline \multicolumn{5}{|l|}{ Sample $11 / 30 / 98$} \\
\hline n-Alkanes $\left(\mathrm{C}_{15}-\mathrm{C}_{32}\right)$ & & 408 & 1065 & 192 \\
\hline CPI & & 0.57 & 0.74 & 0.52 \\
\hline Squalene & & 187 & 340 & 74 \\
\hline Phthalates & & 312 & 288 & 329 \\
\hline PAHs & & 1.41 & 0.66 & 1.17 \\
\hline \multicolumn{5}{|l|}{ Sample $12 / 13 / 98$} \\
\hline n-Alkanes $\left(\mathrm{C}_{15}-\mathrm{C}_{32}\right)$ & & 503 & 926 & 607 \\
\hline CPI & & 0.85 & 0.85 & 0.83 \\
\hline Squalene & & 613 & 615 & 789 \\
\hline Phthalates & & 433 & 304 & 234 \\
\hline PAHs & & 1.92 & 2.98 & 2.34 \\
\hline \multicolumn{5}{|l|}{ Sample $12 / 28 / 98$} \\
\hline n-Alkanes $\left(\mathrm{C}_{15}-\mathrm{C}_{32}\right)$ & & 268 & 220 & 735 \\
\hline CPI & & 0.6 & 0.98 & 0.88 \\
\hline Squalene & & 494 & 543 & 852 \\
\hline Phthalates & & 391 & 215 & 240 \\
\hline PAHs & & 1.58 & 1.68 & 4.42 \\
\hline \multicolumn{5}{|l|}{ Sample 01/09/99 } \\
\hline n-Alkanes $\left(\mathrm{C}_{15}-\mathrm{C}_{32}\right)$ & & 675 & 271 & 267 \\
\hline CPI & & 0.89 & 0.66 & 0.71 \\
\hline Squalene & & 358 & 214 & 554 \\
\hline Phthalates & & 539 & 334 & 391 \\
\hline PAHs & & 1.23 & 1.83 & 2.34 \\
\hline
\end{tabular}

water, and consequently they are also associated with marine aerosol.

Although it could be expected that organic concentrations decrease as altitude increases, our results did not follow this particular trend. Concentration trends appear to be indistinct and could be dependent on climatic variation (i.e. wind direction) and/or on variations of organic compound concentrations in sea water as noted by other authors for the concentrations of anionic and cationic inorganic compounds. ${ }^{44}$ The transfer process of these organic compounds from the sea water to the atmosphere and successively to snow precipitation could be related to the capability of organic matter to be enriched at sea surface by different processes as bubble bursting, diffusion, etc. Bubbles at the sea surface in particular could play an important role not only for surface enrichment, but also for organic matter ejection towards atmosphere. . $^{3,9,11}$

Some authors ${ }^{45}$ proposed the spray drop adsorption model (SDAM) that regards the relationship between the particles dimension of the marine aerosol and the distribution of organic matter in the low atmosphere. On the basis of SDAM, the transition from saline nature particle (largest particles) to an essentially organic nature particle (smallest particles), could offer an alternative explanation to the long-range transport of many pollutants via marine aerosol. ${ }^{46}$ In fact, for rough sea condition (as Antarctic marine storms) marine aerosol reaches the coastal zone with a dimensional selection in relation to the altitude and distance from the sea; small particles are expected to reach longer distances.

In order to evaluate the marine contribution to the organic content of snow, we calculated the ratios between the concentrations of n-alkanes, PAHs and phthalates in "fresh" snow
Table 4 n-Alkanes, phthalates and PAHs in the snow sample 11/30/98 $\left(\mathrm{ng}^{-1}\right)$; medium values of five determinations with standard deviation

\begin{tabular}{|c|c|c|c|}
\hline & $360 \mathrm{~m}$ & $1188 \mathrm{~m}$ & $2670 \mathrm{~m}$ \\
\hline $\mathrm{n}-\mathrm{C}_{8}$ & $4 \pm 1$ & $6 \pm 1$ & $6 \pm 1$ \\
\hline $\mathrm{n}-\mathrm{C}_{9}$ & B.d.l. & B.d.l. & B.d.l. \\
\hline$n-C_{10}$ & $3 \pm 5$ & B.d.l. & $14 \pm 5$ \\
\hline $\mathrm{n}-\mathrm{C}_{11}$ & B.d.l. & B.d.1. & $10 \pm 4$ \\
\hline$n-C_{12}$ & $9 \pm 1$ & $23 \pm 1$ & B.d.l. \\
\hline$n-C_{13}$ & B.d.l. & B.d.l. & B.d.l. \\
\hline$n-C_{14}$ & $2^{a}$ & $2^{a}$ & $2^{a}$ \\
\hline $\mathrm{n}-\mathrm{C}_{15}$ & $2^{a}$ & $2^{a}$ & $6 \pm 1$ \\
\hline$n-C_{16}$ & $13 \pm 2$ & $18 \pm 3$ & $31 \pm 5$ \\
\hline$n-C_{17}$ & $8 \pm 1$ & $2 \pm 0$ & $9 \pm 1$ \\
\hline$n-C_{18}$ & $9 \pm 1$ & $5 \pm 1$ & $10 \pm 2$ \\
\hline$n-C_{19}$ & $9 \pm 2$ & $4 \pm 2$ & $8 \pm 2$ \\
\hline$n-C_{20}$ & $3 \pm 1$ & $6 \pm 1$ & $7 \pm 1$ \\
\hline$n-C_{21}$ & $12 \pm 1$ & $5 \pm 1$ & $5 \pm 1$ \\
\hline$n-C_{22}$ & $31 \pm 1$ & $3 \pm 1$ & $4 \pm 1$ \\
\hline$n-C_{23}$ & $19 \pm 1$ & $24 \pm 1$ & $4 \pm 1$ \\
\hline$n-C_{24}$ & $42 \pm 2$ & $45 \pm 2$ & $10 \pm 2$ \\
\hline$n-C_{25}$ & $21 \pm 2$ & $34 \pm 2$ & $5 \pm 2$ \\
\hline$n-C_{26}$ & $34 \pm 2$ & $136 \pm 2$ & $7 \pm 2$ \\
\hline$n-C_{27}$ & $32 \pm 3$ & $126 \pm 13$ & $6 \pm 1$ \\
\hline$n-C_{28}$ & $88 \pm 3$ & $147 \pm 3$ & $15 \pm 3$ \\
\hline$n-C_{29}$ & $24 \pm 2$ & $136 \pm 14$ & $5 \pm 1$ \\
\hline$n-C_{30}$ & $17 \pm 2$ & $135 \pm 14$ & $6 \pm 1$ \\
\hline$n-C_{31}$ & $14 \pm 1$ & $108 \pm 11$ & $7 \pm 1$ \\
\hline$n-C_{32}$ & $12 \pm 1$ & $98 \pm 10$ & $15 \pm 2$ \\
\hline Total n-alkanes & 408 & 1065 & 192 \\
\hline CPI & 0.57 & 0.74 & 0.52 \\
\hline Squalene & 187 & 340 & 74 \\
\hline $\begin{array}{l}\text { Di- } n \text {-butyl- } \\
\text { phthalate }\end{array}$ & $33 \pm 5$ & $9 \pm 1$ & $66 \pm 10$ \\
\hline $\begin{array}{l}\text { Di-iso-butyl- } \\
\text { phthalate }\end{array}$ & $67 \pm 10$ & $18 \pm 3$ & $98 \pm 15$ \\
\hline $\begin{array}{l}\text { Di-(2-ethyl- } \\
\text { hexyl)phthalate }\end{array}$ & $212 \pm 32$ & $261 \pm 39$ & $165 \pm 25$ \\
\hline Total phthalates & 312 & 288 & 329 \\
\hline FL & $0.292 \pm 0.044$ & $0.321 \pm 0.048$ & $0.194 \pm 0.029$ \\
\hline PHE & B.d.l. & B.d.l. & $0.164 \pm 0.025$ \\
\hline ANT & $0.218 \pm 0.033$ & $0.119 \pm 0.018$ & $0.422 \pm 0.063$ \\
\hline FLT & $0.080 \pm 0.012$ & B.d.1. & $0.083 \pm 0.012$ \\
\hline PY & $0.455 \pm 0.068$ & $0.165 \pm 0.025$ & $0.197 \pm 0.030$ \\
\hline $\mathrm{BaA}$ & $0.051 \pm 0.008$ & B.d.l. & B.d.l. \\
\hline CHRY & $0.040 \pm 0.006$ & $0.015 \pm 0.003$ & $0.016 \pm 0.003$ \\
\hline $\mathrm{BbF}$ & $0.114 \pm 0.017$ & B.d.l. & B.d.l. \\
\hline $\mathrm{BkF}$ & $0.039 \pm 0.004$ & $0.020 \pm 0.003$ & $0.020 \pm$ \\
\hline $\mathrm{BaP}$ & $0.051 \pm 0.008$ & $0.020 \pm 0.003$ & $0.075 \pm 0.011$ \\
\hline DBA & $0.069 \pm 0.010$ & B.d.l. & B.d.l. \\
\hline BghiP & B.d.l. & B.d.1. & B.d.l. \\
\hline IP & B.d.l. & B.d.l. & B.d.l. \\
\hline Total PAHs & 1.41 & 0.660 & 1.17 \\
\hline
\end{tabular}

and sea water samples with respect to the concentrations of sodium ion in the same matrices, which is used as an univocal sea salt marker. In this paper with respect to previous studies, ${ }^{8,15,45}$ we took into account organic compound concentrations in SML instead of in sea water because the air/water interface is expected to be the main contributor of the air-sea exchange.

In brief, we define the Enrichment Ratio (ER) of a generic compound $(\mathrm{X})$ using:

$$
\mathrm{ER}(\mathrm{X})=\left([\mathrm{X}]_{\mathrm{sn}} /\left[\mathrm{Na}^{+}\right]_{\mathrm{sn}}\right) /\left([\mathrm{X}]_{\mathrm{SML}} /\left[\mathrm{Na}^{+}\right]_{\mathrm{SML}}\right)
$$

where sn and SML refer to snow and SML, respectively. Since sodium ion is not enriched during the aerosolization process, its concentration was taken as a quantitative index of marine 


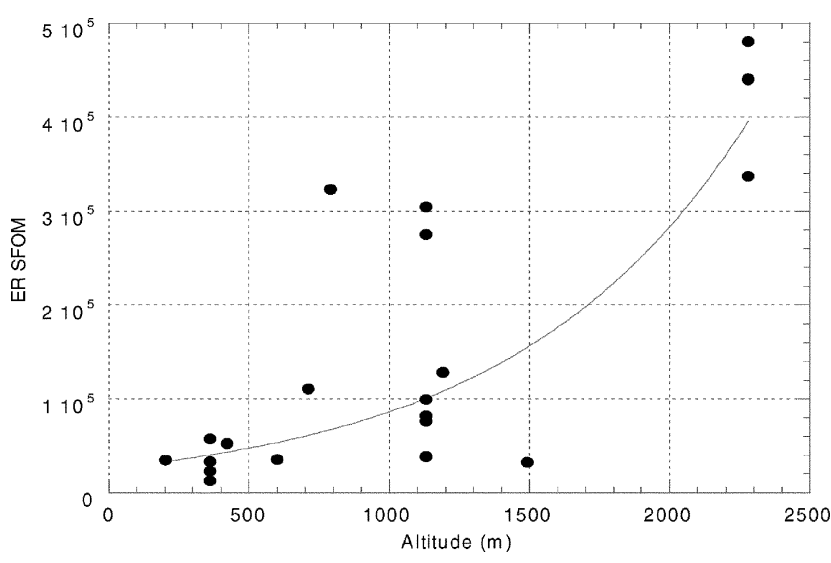

Fig. 4 Enrichment ratio (ER) between surfactant fluorescent organic matter (SFOM) vs. altitude. Snow samplings here reported had been collected from 1993-1994 to 1998-1999 Italian Antarctic campaigns.

aerosol content in the snow. The ratios between the mean concentration of surfactant fluorescent organic matter (SFOM) n-alkanes, phthalates and PAHs in the sea surface microlayer and that of the sodium ion were $7.14 \times 10^{-10}$, $2.78 \times 10^{-8}, 4.412 \times 10^{-8}$ and $5.73 \times 10^{-10}$, respectively.

The data on ER(SFOM), calculated on snow samples collected on Mt Melbourne, between 1993-1994 and 1998-1999, showed an exponential trend with increasing of the altitude above sea level (see Fig. 4). ${ }^{46}$ Substantially, it was noted that the sodium ion concentration decreases in high altitude samples whereas the mass of the fluorescent material increases, as shown in the ER(SFOM). This trend reminds the SDAM model, which

\section{a) SFOM}

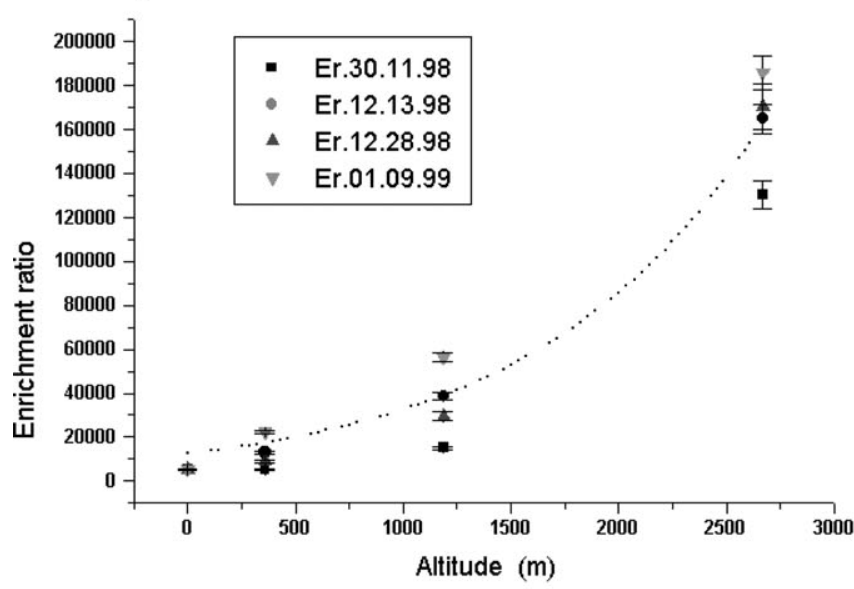

c) n-Alkanes

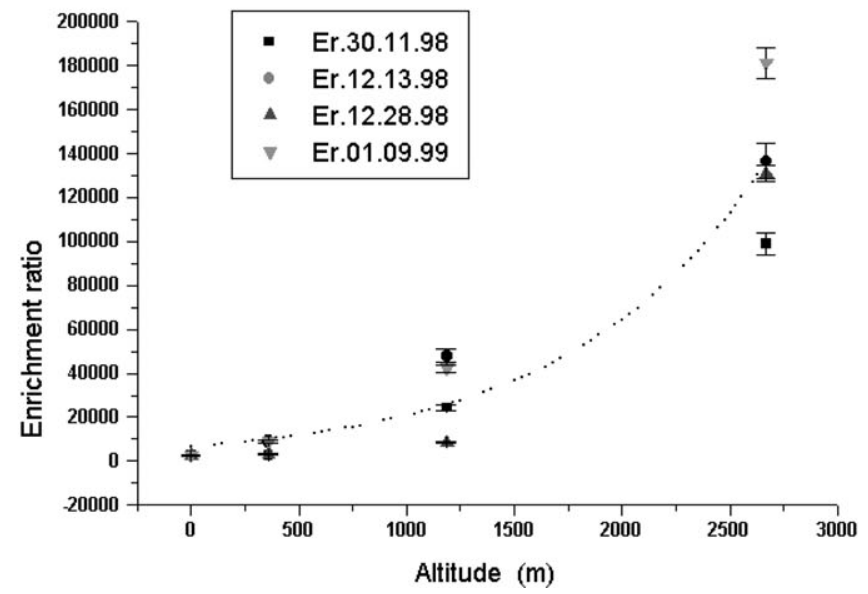

assumes that fine and ultrafine particles are richer of organic matter and reach higher altitudes than largest ones.

As expected, in this study we obtained the same exponential trend for enrichment ratios for SFOM, calculated for all "fresh" snow samples collected at different altitudes (Fig. 5a).

Moreover, greatest ER values at increasing altitude were found for phthalates, n-alkanes and PAHs, as shown in Fig. $5 \mathrm{~b}, \mathrm{c}$ and $\mathrm{d}$. It should be pointed out that ER values vary from class to class, according to their different volatility, surface activity, interaction with particles and behaviour during the snow "scavenging" effect.

The fine and ultrafine particles of marine aerosol, being mainly constituted by surfactant material and reaching high altitudes, may justify the enrichment of phthalates with increasing the altitude above sea-level, because of their surfactants properties. ${ }^{47,48}$

A similar exponential curve was observed for n-alkanes and PAHs, although they are not surfactants. This trend could be explained considering that hydrocarbons can be transported into the liquid aerosol owing to their affinity towards the air bubbles and jet-drops and their capability to interact with the surface active material present at sea surface water, and follow the same fate. n-Alkanes also showed the greatest enrichment as the altitude increases, attributed to the higher percentage of these compounds in SML and to their high hydrophobicity which favours their adsorption on the natural surfactant matter (fulvic acids), as shown by laboratory studies. ${ }^{12}$

\section{Conclusions}

The SML is enriched with n-alkanes, PAHs and phthalates with respect to the SSL. The particulate EFs were greater than

\section{b) Phthalates}

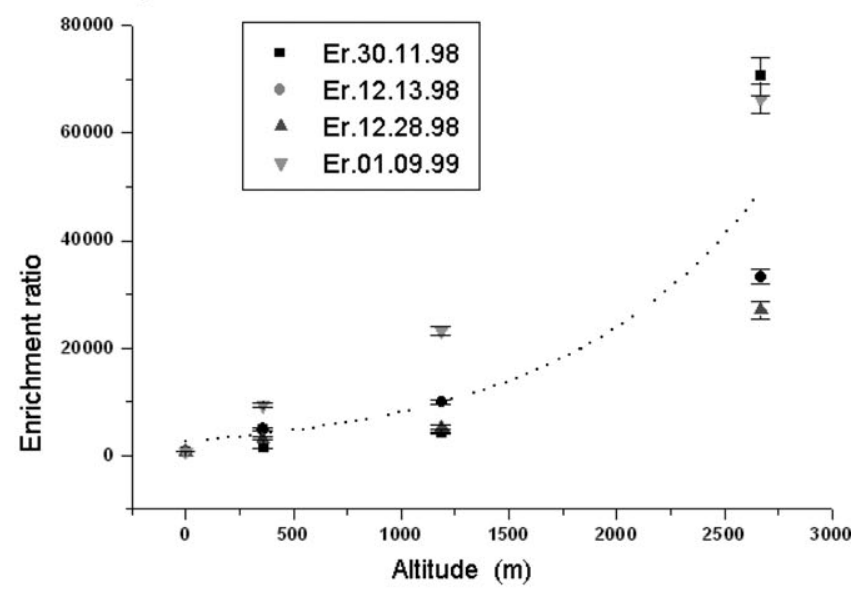

d) PAHs

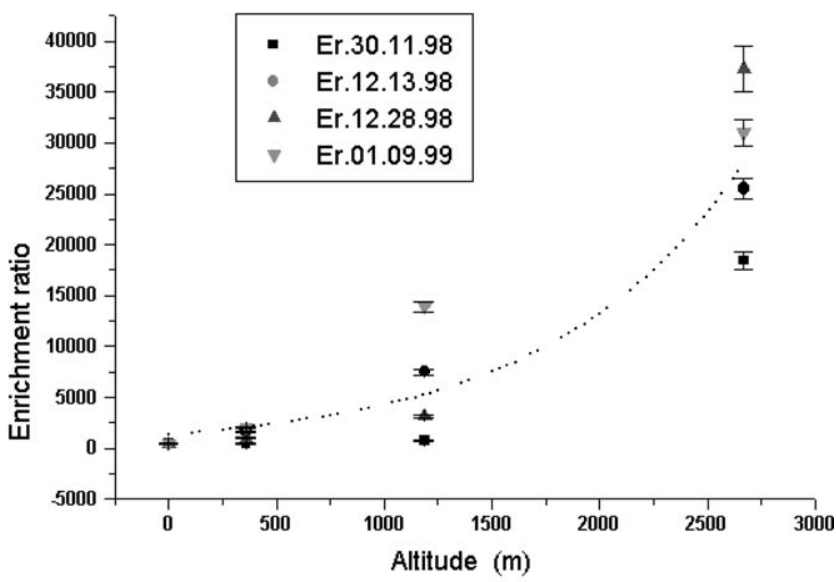

Fig. 5 Enrichment ratios for SFOM, pthalates, n-alkanes and PAHs vs. altitudes. 
the dissolved EFs. The particle-associated enrichments in the SML were largely related to the accumulation of total suspended particles at air/water interface.

The same compounds identified in sea water samples were also present in "fresh" snow. In particular, the "markers" $\mathrm{C}_{16}$, $\mathrm{C}_{24}$ and $\mathrm{C}_{28}$ were the most abundant compounds among $\mathrm{n}$-alkanes and the odd/even carbon number ratios were much lower than one, pointing out a biogenic origin of such chemicals. Organic compounds in "fresh" snow samples did not show a particular trend as altitude increases.

Chemicals found in the SML are transferred to the "fresh" snow samples by marine aerosol and are enriched particularly in the finest particles, which can be involved in the long range transport of pollutants.

The ER values for phthalates, $n$-alkanes and PAHs increase with increasing the altitude above sea level and distance from the coast. The behaviour of phthalates is in agreement with the deposition of the finest marine aerosol particles, mainly constituted by surfactant material, at higher altitudes according to the SDAM. The enrichment of n-alkanes and PAHs could be explained considering the strong affinity of hydrocarbons for the natural fluorescent surfactant matter (fulvic acids) which is abundant in fine and hyperfine aerosol particles.

\section{Acknowledgements}

This study was supported by the Italian National Antarctic Research Programme (PNRA). Many thanks to Professor R. Udisti for sodium ion analysis.

\section{References}

1 G. C. Cripps, Mar. Pollut. Bull., 1992, 24(2), 109-114.

$2 \mathrm{IMO} / \mathrm{FAO} / \mathrm{UNESCO}-\mathrm{IOC} / \mathrm{WMO} / \mathrm{WHO} / \mathrm{IAEA} / \mathrm{UN} / \mathrm{UNEP}$. Joint Group of Experts on the Scientific Aspects of Marine Environmental Protection (GESAMP), The Sea-Surface Microlayer and its Role in Global Change, report or study no. 59, WMO, Geneva, 1995.

3 P. S. Liss and R. A. Duce, The Sea Surface and Global Change, Cambridge University Press, Cambridge, 1997.

4 J. C. Marty, A. Saliot, P. Buat Menard, R. Chesselet and K. A. Hunter, J. Geophys. Res., 1979, 84, 5707-5716.

5 J. C. Marty, V. Zutic, P. Precali, A. Saliot, B. Cosovic, N. Smodlaka and G. Canwet, Mar. Chem., 1988, 25, 243-263.

6 J. T. Hardy, J. A. Coley, L. D. Antrin and S. L. Kiesser, Can. J. Fish. Aquat. Sci., 1988, 45(5), 822-826.

7 J. Knulst and A. Södergren, Chemosphere, 1994, 29(6), 1339-1347.

8 A. M. Cincinelli, M. Stortini, L. Perugini, L. Checchini and L. Lepri, Mar. Chem., 2001, 76, 77-98.

9 J. C. Knulst, D. Rosenberger, B. Thompson and J. Paatero, Langmuir, 2003, 19, 10194-10199.

10 P. Buat-Ménard, in Air-Sea Exchange of Gases and Particles, ed. P. S. Liss and W. N. Slinn, D. Reidel Publishing Co., Dordrecht, Netherlands, 1983, pp. 455-520.

11 D. C. Blanchard, Estuaries, 1989, 12(3), 127-137.

12 R. Cini, P. G. Desideri and L. Lepri, Anal. Chim. Acta, 1994a, 291, 329-340.

13 L. Lepri, P. G. Desideri, R. Cini, F. Masi and M. S. Van Erk, Anal. Chim. Acta, 1995, 317, 149-160.

14 K. E. Gustafson and R. M. Dickhut, Environ. Sci. Technol., 1997, 31, $140-147$.

15 R. Cini, R. Udisti, G. Piccardi, G. Loglio, N. Degli Innocenti, A. M. Stortini, B. Pampaloni and U. Tesei, Int. J. Environ. Anal. Chem., 1998, 71(3-4), 265-287.

16 G. Carrera, P. Fernàndez, R. M. Vilanova and J. O. Grimalt, Atmos. Environ., 2001, 35, 245-254.
17 M. K. Stanley, K. A. Robillard and C. A. Stapes, in Phthlate Esters, ed. C. A. Staples, Springer Verlag, GmbH, Berlin, 2003.

18 M. R. Preston and L. A. Al-Omran, Environ. Pollut., 1989, 62, $183-193$.

19 A. Turner and M. C. Rawling, Mar. Chem., 2000, 68(3), 203-217.

20 C. S. Giam, H. S. Chan, G. S. Neff and E. L. Atlas, Science, 1977 , 199, 419-421.

21 P. G. Desideri, L. Lepri and L. Checchini, Ann. Chim. (Rome), 1989, 79, 589-605.

22 A. Ciccioli, E. Cucinato, E. Brancaleoni, M. Montagnoli and I. Allegroni, Int. J. Environ. Anal. Chem., 1994, 55, 285-295.

23 M. Del Bubba, A. Cincinelli, L. Checchini, L. Lepri and P. G. Desideri, Int. J. Environ. Anal. Chem., 84(6-7), 441-456.

24 G. E. Shaw, Rev. Geograph., 1988, 26, 86-112.

25 E. W. Wolff, Antarct. Sci., 1990, 2, 189-205.

26 M. Stortini, C. Turetta, F. Corami, L. Manodori, S. Ferrari and G. Capodaglio, The Microlayer's role in the transport of micropollutants in the Venice Lagoon. Scientific Research and Safeguarding of Venice, CORILA Research Program 2001 results, ed. P. P. Campostrini, Istituto Veneto di Scienze, Lettere ed Arti, Venezia and CORILA, Venezia, 2002, p. 459.

27 G. W. Harvey, Limnol. Oceanogr., 1966, 11, 608-614

28 P. G. Desideri, L. Lepri and L. Checchini, Mikrochim. Acta, 1992, 107, 55-63.

29 P. G. Desideri, L. Lepri, M. Canovaro and L. Checchini, in Chemistry for Protection of the Environment, ed. L. Pawlowski, E. Mentasti, W. J. Lacy and C. Sarzanini, Elsevier, Amsterdam, 1987, pp. 317-332.

30 P. G. Desideri, L. Lepri, L. Checchini, D. Santianni, F. Masi and M. Bao, Int. J. Environ. Anal. Chem., 1995, 61, 318-330.

31 N. Degli Innocenti, PhD thesis, University of Pisa, Italy, 1993.

32 R. Cini, N. Degli Innocenti, G. Loglio, G. Orlandi, A. M. Stortini and U. Tesei, Int. J. Environ. Anal. Chem., 1994b, 55, 285-295.

33 R. Udisti, R. Bellandi and G. Piccardi, Fresenius' J. Anal. Chem., 1994, 349, 289-293.

34 G. Cincinelli, P. G. Desideri, L. Lepri, L. Checchini, M. Del Bubba and R. Udisti, Int. J. Environ. Anal. Chem., 2001b, 79(4), 283-299.

35 G. Green, J. H. Skerratt, R. Leeming and P. D. Nichols, Mar. Pollut. Bull., 1992, 25(9-12), 293-302.

36 J. Sanchez-Pardo and J. Rovira, Hidrocarburos alifaticos y aromaticos policiclicos detectados en aguas del Estrecho de Bransfield. Expedicion BIOMASS III (Antarctic '86), in CASTELL VI, Ed. Actas del Segundo Symposium Espanol de studios Antarticos, Coseno Superior de Investigazione Cientificas, Madrid, 1987, pp. $117-124$.

37 G. C. Cripps, Polar Biol., 1990, 10, 393-402.

38 G. C. Cripps and J. Priddle, Antarct. Sci., 1995, 7(2), 127-136.

39 O. Mangoni, M. Modigh, F. Conversano, G. C. Carrada and V. Saggiomo, Deep-Sea Res., Part I, 2004, 51(II), 1601-1617.

40 G. C. Cripps, Deep-Sea Res., Part II, 1995, 42(4-5), 1123-1135.

41 J. F. Rontani and J. K. Volkman, Org. Geochem., 2003, 34, 1-35.

42 P. A. Meyers and J. G. Quinn, Nature, 1973, 244, 23-24.

43 R. Comes, L. Ventajas and S. Kocmur, Hidrocarbons polinucleares en el Mar de Weddell, in Primer Symposium Espanol de Estudios Antarticos, Consejo Superior de Investigaciones Cientificas, Madrid, 1987, pp. 285-290.

44 R. Udisti, E. Castellano, S. Becagli, R. Traversi and G. Piccardi, Proceedings of the $V I^{\circ}$ Convegno Nazionale "Evoluzione e Cicli Biogeochimici dei Contaminanti”, Ca' Dolfin Dorsoduro, Venezia, 27-28 Aprile 1998, pp. 41-50.

45 C. Oppo, S. Bellandi, N. Degli Innocenti, A. M. Stortini, G. Loglio, E. Schiavuta and R. Cini, Mar. Chem., 1999, 63, 235-253.

46 M. Stortini, R. Cini, R. Traversi and R. Udisti, VIII ${ }^{\circ}$ Workshop sull'Atmosfera Antartica Bologna 20-22 Ottobre 1999, C.N.R.Area Bologna Conference proceedings, "Italian Research on the Antarctic Atmosphere”, ed. M. Colacino and G. Giovannelli, SIF, Bologna, 2000, vol. 69, pp. 411-420.

47 R. Cini, P. G. Desideri and L. Lepri, Anal. Chim. Acta, 1994, 291, 329-340.

48 M. Thomsen, L. Carlsen and S. Hvidt, Environ. Toxicol. Chem., 2001, 20(1), 127-132. 